\title{
Construction of high-quality resource sharing course based on large-scale online open platform-a case study of "introduction to clinical medicine" course
}

\author{
Mingyan Yua ${ }^{\mathrm{a}}$, Yonghua Xuan, Hong Xu, Changyong Lin, Cheng Zhang \\ Binzhou Vocational College, Shandong, 256600, China \\ aemail: yumingyan1977@163.com
}

Keywords: Online open platform; Quality resource sharing course; Introduction to clinical medicine

\begin{abstract}
An introduction to clinical medicine is a professional medical rehabilitation technology specialized core curriculum, is closely related to clinical rehabilitation treatment technology, high skills requirements, more knowledge, to conduct training courses can not meet today's requirements, according to the characteristics of the course, in the past five years, the course team combined with the goal of cultivating the students' characteristics and requirements, based on the large-scale online open platform, make full use of micro simulation software, $3 \mathrm{~d}$ animation, video, micro class, such as a variety of resources and methods, build the high-quality goods curriculum resources sharing, and used in the actual teaching process, practice has proved the teaching effect is good.
\end{abstract}

\section{Introduction}

The main purpose of constructing the sharing course of high-quality resources is to cultivate technical and technical rehabilitation talents[1][2]. As the main line, relying on the enterprise, the integration of all resources, based on service in the province, we will built on behalf of the provincial level, has the characteristics of higher vocational education rehabilitation technology professional excellent resource sharing lessons on introduction to clinical medicine and establish a set of teaching, skills upgrading, employment training and job title examination in an open digital professional service platform, so as to promote the province of the course of "introduction to clinical medicine teaching reform and development, and overall improve the quality of the teaching of an introduction to clinical medicine in our province[3][4]. Gradually optimize the curriculum team and build a curriculum team with reasonable structure, stable personnel, high teaching level and good teaching effect. With the joint efforts of the members of the course group, "introduction to clinical medicine" was built into a high-quality resource sharing course with distinctive features, high teaching level and certain leading role[5][6].

\section{Define the objectives of curriculum construction}

The construction objective of this course is to make the course suitable for the learning needs of college students and social beginners of medical rehabilitation and treatment technology major of higher vocational colleges. At the same time, it can enter the follow-up course smoothly through the study of curriculum development resources and achieve the goal of talent training. In terms of the specific construction of curriculum resources, the large-scale online open platform is taken as the carrier to integrate and upload various teaching resources. The construction of basic resources is mainly in the form of text, courseware and video, covering all teaching materials, video of micro-course, operating rules, test questions, case library and animation library required for course learning. The development resources mainly include the front-line development of the major, the text resources required for the development of knowledge and skills, video of micro-course, and student works, so as to make the sharing of the course content of high-quality resources closely related to the needs of talents, ensure the practicability of resource construction, and be suitable for self-study and self-assessment of school students and social learners. 


\section{Explore the idea of curriculum construction}

Reintegrate and update the original course resources, add a large number of video materials and animation materials, and upload and update resources on the "large-scale open platform" website. Gradually refine the course content, collect cases from the clinic, keep filling and updating, and keep updating the course project according to the real clinical work process of the hospital. The existing structured teaching resources are fragmented to increase the types of resources, such as video, animation and micro-video in students' practical operations, and increase the proportion of learning guidance, online testing and other resources. Optimize course resources to help students master knowledge and skills, and further improve their use of resources before, during and after class. Teachers publicize the advantages of the teaching platform, issue the user manual, and communicate with students online and offline through the teaching platform before, during and after class. It includes preview of new courses, analysis of cases, assignment and submission of assignments, tests, answering questions, etc., so that students can learn more flexibly and conveniently, thus improving their learning efficiency.

\section{Formulate Curriculum design}

\subsection{Course orientation}

\subsubsection{Training goal of rehabilitation and treatment technology professional}

This professional major trains high-quality technical skilled personnel who support the party's basic line, have good professional ethics and professional career development foundation, can work in the rehabilitation of the rehabilitation industry a line of moral, intellectual, physical, all-round development for comprehensive hospitals, medical institutions at all levels, such as children's rehabilitation institution enterprise (matter) industry unit.

\subsubsection{Requirements of rehabilitation and treatment technology post}

The professional posts of rehabilitation and treatment technology are rehabilitation therapists and rehabilitation teachers, etc. Qualified personnel for the post of employment capacity require many skills. They need good command of clinical rehabilitation techniques, operating procedures and operating specifications. They should have the ability to propose job related business problems, analyze problems independently and solve problems preliminarily, ability to learn independently and obtain certificates from rehabilitation therapists at all levels. They should also have good computer and English skills, good professional quality, teamwork and quality awareness, good psychological quality and interpersonal communication skills.

\subsubsection{Course status}

Introduction to clinical medicine is a professional core course based on the work ability requirement of the post of rehabilitation technology, which plays an important role in the training of medical rehabilitation technology professionals. This course is offered in the second semester for a total of 136 hours. Students have already taken the leading courses, such as "human form and function", "pharmacology", "fundamentals of disease" and other basic courses. They have a certain basic knowledge and skills of normal body structure and pathology. The course of introduction to clinical medicine lays a foundation for the further study of medical rehabilitation technology. At the same time, it lays a necessary foundation for the diagnosis of diseases in clinical rehabilitation work and the determination of rehabilitation treatment project, which can stimulate students' interest in learning.

\subsubsection{The teaching goal}

We determine the teaching objectives according to curriculum standards and vocational requirements, including knowledge objectives, ability objectives and quality objectives. Knowledge objectives include to be familiar with basic diagnostic knowledge, be familiar with clinical features and diagnosis basis of common clinical diseases and understand the principle of prevention and 
treatment of common clinical diseases. Ability objectives include to be able to describe the basic characteristics of common clinical diseases and be familiar with the diagnosis and treatment of common clinical diseases. Quality objectives include that we should develop a scientific attitude of seeking truth from facts and seriously and cultivate professional qualities of doctor-patient communication and humanistic care. At the same time we should have the spirit of dedication, solidarity and cooperation. The relationship between the professional team and clinicians should be properly handled.

\subsection{Content selection}

\subsubsection{Selection principle of teaching content}

The goal is to train medical rehabilitation technical personnel.

The basement is on clinical rehabilitation projects.

Break the traditional mode and turn to choose teaching content around the rehabilitation program. In close combination with students' cognitive laws, a certain logical relationship is formed between clinical work projects.

Teaching, learning, and doing are integrated into the learning process of clinical work projects.

It reflects sustainable development and provides students with advantages in employment, the ability to start a business and a foundation for lifelong learning.

\subsubsection{Determine teaching content}

We analyze the course objective to select the teaching content through the discussion with the hospital rehabilitation expert, according to the medical rehabilitation technical post capacity demand and the corresponding work task. According to the law of vocational training of medical students in higher vocational colleges, two teaching projects of the course were determined according to the real clinical working situation. Based on the work process and the real work task of clinical rehabilitation, the teaching content of the course of introduction to clinical medicine was integrated into a typical work task. The total period is 136 hours. All the learning tasks are completed in the on-campus training room and off-campus teaching hospital, and the integrated teaching of theory and practice is implemented.

\subsection{Content organization}

In the organization and arrangement of teaching content, two typical projects and 12 typical tasks were designed based on the actual working process of clinical rehabilitation post. Design the learning objective, learning content, learning method, learning environment, teaching media, evaluation method, knowledge reserve of students and requirements of teachers' knowledge and ability for each task. Teaching content is organized by combining in-class and after-class projects, online learning and offline learning, as well as individual training programs and comprehensive training programs. And clinical quality control, doctor-patient communication, humanistic care and other professional quality education throughout.

\subsection{Teaching mode}

\subsubsection{Implement the "project oriented" teaching mode by relying on the industry.}

Wang li, song binof Affiliated hospital of binzhou medical college and wang zhonggong, li jichang of binzhou people's hospital, as well as the clinical frontline "skilled craftsmen", were employed as part-time teachers. We develop the project-oriented teaching model according to the post group, so that the students can become qualified skilled professionals as soon as possible. The whole course teaching takes students as the subject and implements the integration of teaching and training evaluation. It fully reflects students' seamless learning both online and offline, and interactive learning both in and out of class. It fully reflects the seamless link between teaching and clinic, and gives full play to students' subjective initiative in learning. 


\subsubsection{Using various informationization means, carry out the informationization teaching mode, solve the traditional teaching difficulty.}

In the implementation process of the project teaching, before each class, the teacher publishes the real cases online, and assigns work tasks for the next class. Before class, students can watch micro classes, video, animation, expert lectures, photo library, operating procedures and other information resources through the teaching platform, and use the forms of independent learning, peer learning, role playing to complete the learning and each work task. In class, teachers use teaching software, virtual simulation and other forms of teaching integration. Through the simulation work task between the teams, the implementation plan is made, and the evaluation plan is made by the group students and teachers. The teacher guides, corrects and answers questions on the spot, and finally carries out project evaluation and assessment, and answers students' questions immediately after class.

\subsection{Curriculum resources}

After years of building the course team, this course has gradually built a three-dimensional network teaching resource with rich contents and various forms. The resources include basic resources and expansion resources. Basic resources include text, PPT, micro-course video, animation and other materials required by the course, online and offline, and knowledge and skills quality objectives. The expansion resources include case library, reference resource library, picture library, video library and healthy education

\section{Enhanced safeguards}

\subsection{Make policy and support it}

In order to ensure the long-term, serious and sustainable construction of course resources, the college has developed a series of policy documents to support the construction of quality resource base. A series of documents have been issued to put forward new ideas and measures for the course construction reform of quality resources.

\subsection{Organize and strengthen leadership}

In order to strengthen the organization and leadership of curriculum construction, a two-level curriculum resource base construction organization consisting of the department and the department has been established.

\subsection{Ensure funding and increase input}

All the courses approved by the college are approved in the form of construction projects, with financial support. The university-level curriculum construction implements the matching of 10,000 yuan for the two levels of the department. The college provides 1:1 matching support to the provincial or national fund appropriated by the project sponsor of provincial or national quality resource database。It provides favorable financial support for the construction of the quality resource base.

\section{Conclusion}

Construction of large-scale online open course platform of introduction to clinical medicine,a large amount of video materials and animation materials are added, providing convenient conditions for students to learn independently by reintegrating and updating the original course resources. The program of "online communication" is set up to realize the interaction and communication between teachers and students on the Internet and answer questions for students. It provides more abundant learning resources, enables students to strengthen their autonomous learning ability through online learning platform, and lays a good foundation for the cultivation of lifelong learning habit and ability. 


\section{References}

[1] Pan bingchao. Experimental study on the application of flipped classroom model in higher education [J]. EducationStudy, 2015(3):83-88.

[2] Luo dongmei. Design and implementation of teaching process under the mixed learning model [J]. Modern education technologyShu, 2010(10):36-40.

[3] He shuiying, wu tao. Practical research on informationized teaching model and traditional teaching model [J]. healthCareer education, 2017,35(9):29-30.

[4] Geng baoyang, wang xiaoling. Problems and countermeasures in informatization teachingin higher vocational colleges [J]. Jiangsu province Education study, 2017(12):39-41.

[5] Wang hongyan. An empirical study on flipped classroom teaching model of higher vocational English supported by yun class [J].Modern education essays,2016 (1):43-51.

[6] Jiao Jie. A study on "learner centered" classroom teaching mode based on "cloud" teaching platform[J].The electronic world,2016(18):48. 